\title{
Persepsi Masyarakat Terhadap Adanya Sangsi Adat (Studi Kasus di Desa Pinang Merah Kecamatan Pamenang Barat Kabupaten Merangin Provinsi Jambi)
}

\author{
Uying Hapid Alatas ${ }^{1}$, Sri Utami \\ 1,2 Jurusan Pendidikan Luar Sekolah STKIP YPM Bangko-Jambi \\ uyinghapidalatas@ymail.com
}

\begin{abstract}
Abstrak
Hukum adat adalah peraturan tingkah laku manusia dalam kehidupan sehari-hari, senantiasa ditaatai dan dihormati karena mempunyai akibat hukum atau sanksi atas pelanggaran yang sudah dilakukan. Namun fakta dilapangan menunjukkan bahwa pelanggaran adat banyak terjadi setiap tahunnya. Pelanggaran yang sering terjadi adalah kawin lari. Tujuan penelitian ini untuk mengetahui kenapa pelanggaran adat kawin lari semakin meningkat di Desa Pinang Merah dan untuk mengetahui apakah pelaksanaan sanksi adat untuk kawin lari sesuai dengan aturan adat yang berlaku di Desa Pinang Merah serta untuk mengetahui bagaimana persepsi masyarakat terhadap sanksi adat kawin lari di Desa Pinang Merah. Penelitian ini menggunakan pendekatan studi kasus dengan metode penelitian kualitatif deskriptif. Teknik pengumpulan nya dengan observasi, wawancara dan dokumentasi. Informan dalam penelitian ini berjumlah 5 (Lima) orang masyarakat dengan Teknik pemilihan informan menggunakan Purposive sampling. Teknik analisis data dalam penelitian ini Reduksi data, penyajian data dan kesimpulan. Teknik penjamin keabsahan data Credibility, Transferability, Dependability dan Comfirmability. Berdasarkan hasil analisis data ditemukan bahwa menigkatnya pelanggaran adat kawin lari karena kurangnya pengawasan dan bimbingan orang tua terhadap anak. Anak tidak dikontrol dengan baik, yang mengakibatkan anak terlibat pergaulan bebas. Kawin lari merupakan salah satu akibat dari pergaulan bebas. Untuk pelaksanaan sanksi adat ditemukan bahwa Pelaksanaan sanksi adat kawin lari di Desa Pinang Merah belum terlaksana dengan baik. Karena masih banyak terjadi pelanggaran adat kawin lari. Sedangkan persepsi masyarakat terhadap sanksi adat kawin lari yaitu sanksi adat merupakan aturan yang harus dipatuhi oleh masyarakat. sanksi merupakan warisan turun temurun dari nenek moyang zaman dahulu yang masih dipakai sampai sekarang. Namun pada kenyataannya sanksi adat kawin lari belum terlaksana dengan baik karena masih terjadi tebang pilih atau pilih kasih antara masyarakat. Saran dalam penelitian ini adalah Masyarakat hendaknya mematuhi aturan adat Desa yang berlaku di Desa Pinang Merah dengan membayar sanksi adat yang diberikan oleh lembaga adat sebagai tanda telah melakukan kesalahan. Lembaga adat agar dapat memberikan pemahaman kepada masyarakat supaya mengikuti aturan adat Desa Pianang Merah, agar dapat mengurangi pelanggaran sangsi adat.

Kata kunci: Masyarakat, Sanksi Adat, Persepsi
\end{abstract}




\begin{abstract}
Customary law is a rule of human behavior in everyday life, always respected and respected because it has legal consequences or sanctions for violations that have been committed. However, the facts in the field show that many customary violations occur every year. The most common violation is kawin lari. The purpose of this research is to find out why the kawin lari customary violation is increasing in Pinang Merah Village and to find out whether the implementation of customary sanctions for kawin lari is in accordance with the customary rules that apply in Pinang Merah Village and to find out how the community's perception of the traditional kawin lari sanction in Pinang Village. Red. This research uses a case study approach with descriptive qualitative research methods. The collection technique uses observation, interview and documentation. The informants in this study amounted to 5 (five) people with the informant selection technique using purposive sampling. Data analysis techniques in this study were data reduction, data presentation and conclusions. Techniques for ensuring the validity of data Credibility, Transferability, Dependability and Comfirmability. Based on the results of data analysis, it was found that the increase in violations of the kawin lari custom was due to the lack of parental supervision and guidance towards children. Children are not well controlled, which results in children engaging in promiscuity. Elopement is one of the consequences of promiscuity. For the implementation of customary sanctions, it was found that the implementation of the traditional kawin lari sanction in Pinang Merah Village has not been implemented properly. Because there are still many violations of the kawin lari custom. Meanwhile, the community's perception of the kawin lari customary sanction is that it is a rule that must be obeyed by the community. sanctions are a hereditary inheritance from their ancient ancestors and are still used today. However, in reality, the customary sanction of kawin lari has not been implemented properly because there is still selective cutting or favoritism between the community. The suggestion in this research is that the community should obey the village customary rules that apply in Pinang Merah Village by paying customary sanctions given by the customary institution as a sign of having done something wrong. Customary institutions in order to provide understanding to the community to follow the customary rules of Pianang Merah Village, in order to reduce violations of customary sanctions.
\end{abstract}

\title{
Keywords: Community, Customary Sanctions, Perception
}

\section{PENDAHULUAN}

Hukum adat adalah peraturan tidak tertulis yang tumbuh dan berkembang didalam masyarakat yang hanya ditaati oleh masyarakat yang bersangkutan. Setiap bangsa di dunia mempunyai adat kebiasaaan masing-masing, antara adat yang satu dengan adat yang lain berbeda-beda. Secara etimologis istilah adat terdiri dari dua kata, yaitu sanksi yang bertujuan memberikan ketertiban dalam pergaulan manusia sehingga keamanan dan ketertiban terpelihara. Sedangkan adat merupakan pencerminan dari kepribadian suatu bangsa, merupakan penjelmaan dari jiwa bangsa yang bersangkutan dari abad ke abad. Berdasarkan hasil wawancara dengan Sekretaris Lembaga Adat. Dengan hasil bahwasanya Setiap lembaga adat memiliki sanksi adat. Apabila masyarakat melanggar aturan adat, maka akan dikenakan sanksi adat.

Seperti Dalam hal perkawinan dilembaga adat diatur tata cara perkawinan. Apabila dilanggar masyarakat akan dikenakan sanksi adat. Seperti kawin lari adalah suatu pelangaran adat. Karena merupakan perbuatan yang tidak seharusnya dilakukan oleh kedua pasangan, perbuatan tersebut sangat merugikan orang tua. Sebelum perkawinan seharusnya didahului oleh acaraseorang gadis dengan seorang pemuda sebagai tunangannya. Peminangan merupakan tanda telah adanya ikatan antara seorang laki-laki dengan seorang perempuan 
yang akan menikah. Ikatan tersebut akan dilanjutkan dengan tata cara pernikahan atau perkawinan yang ditandai dengan akad nikah.

Apabila suatu perkawinan dilakukan dengan cara kawin lari maka dari lembaga adat akan dikenakan sanksi adat. Meski sudah adanya sanksi adat yang ditetapkan lembaga adat, tetapi masih terdapat juga masyarakat yang melanggar adat perkawinan seperti kawin lari. Sanksi adat merupakan hal yang harus dipatuhi, karena setiap sanksi adat adalah sebuah tanda pertanggung jawaban atas pelanggaran yang sudah dilakukan. Apabila sanksi adat tersebut tidak dijalankan maka akan menimbulkan Pro dan Kontra antara masyarakat. Namun fakta dilapangan menunjukkan bahwa pelanggaran adat banyak terjadi seperti ditahun 2018 pelanggaran adat berjumlah 20 orang sedangkan pada Tahun 2019 meningkat menjadi 25 orang. Pelanggaran-pelanggaran adat yang terjadi seperti Kawin Lari, Memutuskan pertunangan, Pencurian, perzinahan dan Berkelahi.

Melihat fenomena diatas maka dipandang perlu diteliti Persepsi Masyarakat terhadap Adanya sangsi adat (Studi Kasus Di Desa Pinang Merah Kecamatan Pamenang Barat Kabupaten Merangin). Penelitian ini bertujuan untuk:

1. Untuk mengetahui kenapa pelanggaran adat kawin lari semakin meningkat di Desa Pinang Merah Kecamatan Pamenang Barat Kabupaten Merangin;

2. Untuk mengetahui apakah pelaksanaan sanksi adat untuk kawin lari sesuai degan aturan adat di Desa Pinang Merah Kecamatan Pamenanag Barat Kabupaten Merangin;

3. Untuk mengetahui bagaimana persepsi masyarakat terhadap sanksi adat kawin lari di Desa Pinang Merah Kecamatan Pamenang Barat Merangin.

\section{KAJIAN TEORI}

Menurut Sarwono dalam Listyana \& Hartono (2013:121), Mengemukakan bahwa Persepsi merupakan proses perolehan, penafsiran, pemilihan dan pengaturan informasi indrawi. Persepsi terjadi apabila seseorang menerima stimulus dari dunia luar yang diterima oleh organ-organ bantunya yang kemudian masuk ke dalam otak. Proses interaksi tidak terlepas dari cara pandang atau persepsi satu individu terhadap individu yang lain, sehingga akan memunculkan yang dinamakan persepsi masyarakat. Persepsi masyarakat tersebut menghasilkan suatu penilaian terhadap sikap, perilaku dan tindakan seseorang didalam kehidupan sehari-hari.

Bentuk-bentuk persepsi yaitu persepsi melaui indera penglihatan, persepsi melalui indera pendengaran, persepsi melalui indera penciuman, persepsi melalui indera pengecap dan persepsi melalui ndera peraba (kulit). Menurut Soetomo dalam Mayangsari (2017:4) Masyarakat adalah kesatuan yang selalu berubah yang hidup karena proses masyarakat. Masyarakat terbentuk melalui hasil interaksi yang kontinyu antar individu. Dalam kehidupan bermasyarakat saling pengaruh mempengaruhi antar kehidupan individu dengan kehidupan bermasyarakat. Adapun macam-macam masyarakat yaitu masyarakat modern dan masyarakat tradisional.

Menurut Soepomo dalam Manarisip (2012:25) Hukum adat adalah sinonim dari hukum tidak tertulis didalam peraturan legislative, hukum yang hidup sebagai konvensi di badan-badan Negara (parlemen, dewan provinsi, dan sebagainya, hukum yang hidup sebagai peraturan kebiasaan yang dipertahankan dalam pergaulan hidup, baik di kota maupun di desadesa). Hukum adat pada umumnya tidak tertulis yaitu kompleks norma-norma yang bersumber pada perasaan keadilan rakyat yang berkembang meliputi peraturan tingkah laku manusia dalam kehidupan sehari-hari, senantiasa ditaati dan dihormati karena mempunyai akibat hukum atau sanksi. 


\section{METODE PENELITIAN}

Penelitian ini menggunakan pendekatan studi kasus dengan metode kualitatif deskriptif yaitu penelitian yang lebih menekankan kepada penalaran, gambaran, analisis dan definisi suatu sistem tertentu, lebih banyak meneliti hal-hal yang berhubungan dengan kehidupan sehari-hari dan diperkuat oleh pendapat ahli. Menurut Sugiyono (2010:15) Metode penelitian kualitatif adalah metode yang berdasarkan pada filsafat postpositivisme, digunakan untuk meneliti pada kondisi obyek yang alamiah, dimana peneliti adalah sebagai instrument kunci, pengambilan sampel sumber data dilakukan secara purposive dan snowbaal, teknik pengumpulan dengan triangulasi (gabungan). Analisis data bersifat induktif atau kualitatif, dan hasil penelitian kualitatif lebih menekankan makna dari pada generalisasi.

Penelitian ini dilakukan di Desa Pinang Merah yang terletak di Kecamatan Bangko Barat Kabupaten Merangin merupakan salah satu Desa dari 5 Desa yaitu Desa Papit, Desa Simpang Limbur, Desa Lagling, Desa Mampun Baru, Desa Pulau Tujuh Wilayahnya sebagian besar merupakan mata pencaharian petani, pegawai negeri sipil, pegawai swasta, pedagang, pertukangan, pensiunan ataupun jasa dan lain sebagainya.

Penelitian dilakukan dari bulan maret sampai dengan bulan juni tahun 2020.Teknik pengumpulan data dilakukan oleh peneliti untuk memperoleh informasi data-data yang diinginkan, peneliti dalam hal ini menerapkan beberapa metode observasi, wawancara dan dokumentasi.

Dalam penelitian ini yang menjadi informan masyarakat Desa Pinang Merah. Peneliti menetapkan 5 informan dari masyarakat yang berada di desa Pinang Merah Kecamatan Bangko Barat Kabupaten Merangin. Langkah-langkah melakukan analisis data kualitatif yaitu:

\section{Data Reduction (Reduksi data)}

Data yang diperoleh dari lapangan jumlahnya cukup banyak, untuk itu maka perlu dicatat secara teliti dan rinci. Seperti telah dikemukan, makin lama peneliti dilapangan, maka jumlah data akan makin banyak, kompleks dan rumit. Untuk itu perlu segera dilakukan analisis data melalui reduksi data. Mereduksi data berarti merangkum, memilah hal-hal yang pokok, memfokuskan pada hal-hal yang penting, dicari tema dan polanya dan membuang yang tidak perlu. Dengan demikian data yang telah direduksi akan memberikan gambaran yang lebih jelas, dan mempermudah peneliti untuk melakukan pengumpulan data selanjutnya, dan mencarinya bila diperlukan.

\section{Data Display (Penyajian Data)}

Setelah data direduksi, maka langkah selanjutnya adalah mendisplaykan data. Dalam penelitian kualitatif, penyajian data bisa dilakukan dalam bentuk uraian singkat, bagan, hubungan antar kategori dan sejenisnya. Yang paling sering digunakan untuk menyajikan data dalam penelitian kualitatif adalah dengan teks yang bersifat naratif. Dengan mendisplaykan data, maka akan mempermudah untuk memahami apa yang terjadi, merencanakan kerja selajutnya berdasarkan apa yang telah dipahami tersebut.

\section{Conclusion Drawing/verification (Kesimpulan/verifikasi)}

Langakah ke tiga dalam analisis data kualitatif menurt Miles dan Huberman adalah penarikan kesimpulan atau verifikasi. Kesimpulan awal yang dikemukan masih bersifat sementara, dan akan berubah bila tidak ditemukan bukti-bukti yang kuat yang mendukung pada tahap pengumpalan data berikutnya. Tetapi apabila kesimpulan yang dikemukan pada tahap awal, didukung oleh bukti-bukti yang valid dan konsisten saat peneliti kembali ke lapangan 
mengumpulkan data, maka kesimpulan yang dikemukakan merupakan kesimpulan yang kredibel.

untuk membuktikan apakah penilitian yang dilakukan benar-benar penelitan ilmiah sekaligus untuk menguji data yang diperoleh. Uji keabsahan data dalam penelitian kualitatif meliputi uji credibility, transferability, dependability, dan confirmability (Sugiyono, 2010: 366). Adapun uji keabsahan data adalah sebagai berikut:

\section{Uji kredibilitas (Credibility)}

Uji Kredibilitas atau uji kepercayaan terhadap data hasil penelitian yang disajikan oleh peneliti agar hasil penelitian yang dilakukan tidak meragukan sebagai karya ilmiah dilakukan.

a. Perpanjangan pengamatan

b. Meningkatkan ketekunan

c. Triangulasi sumber, Trianggulasi Teknik dan Triangulasi waktu

d. Menggunakan Bahan referensi

e. Mengadakan member check

\section{Transferability}

Transferability merupakan validitas eksternal dalam penelitian kualitatif. Validitas eksternal menunjukkan derajad ketepatan atau dapat diterapkan hasil penelitian ke populasi dimana sample tersebut diambil. Nilai transfer berkenaan dengan pertanyaan, hingga mana hasil penelitian dapat diterapkan atau digunakan dalam situasi lain. Bagi peneliti naturakistik, nilai transfer bergantung pada pemakai, hingga manakalahasil penelitian dapat digunakan dalam konteks dan di situasi lain.

\section{Dependability}

Dependability dalam penelitian kualitatif disebut reliabelitas atau penelitian yang dapat dipercaya. Penelitian yang reliabel adalah apabila orang lain dapat mengulangi/mereplikasi penelitian tersebut. Pengujian dependability dilakukan dengan melakukan audit terhadap keseluruhan proses penelitian. Dengan cara auditor yang independen atau pembimbing untuk mengaudit keseluruhan aktivitas peneliti dalam melakukan penelitian. Bagaimana peneliti mulai menentukan masalah/fokus, terjun ke lapangan, menetukan sumber data, melakukan analisis data, melakukan uji keabsahan data, sampai pada pembuatan laporan hasil pengamatan.

\section{Confirmability}

Confirmability dalam penelitian kualitatif disebut pengujian objektivitas penelitian. Penelitian dikatakan objektif bila hasil penelitian telah disepakati banyak orang. Dalam penelitian kualitatif, uji konfirmability mirip dengan uji dependability, sehingga pengujiannya dapat dilakukan secara bersamaan. Menguji konfirmability berarti menguji hasil penelitian, dikaitkan dengan proses yang dilakukan. Bila hasil penelitian merupakan fungsi dari proses penelitian yang dilakukan, maka penelitian tersebut telah memenuhi standard konfirmability.

\section{HASIL DAN PEMBAHASAN}

Penelitian ini dilaksanakan di Desa Pnang Merah Kecamatan Pamenang Barat Kabupaten Merangin yang berjarak $\pm 16 \mathrm{Km}$ dari pusat kota. Desa Pinang Merah merupakan salah satu desa yang berada diwilayah Kecamatan Pamenang Barat Kabupaten Merangin. Luas wilayah Desa Pinang Merah $\pm 8.500 \mathrm{~m}^{2}$. Berdasarkan hasil penelitian dilapangan 
dengan teknik pengumpulan data observasi, wawancara dan dokumentasi terhadap beberapa informan penelitian.

\section{Alasan Pelanggaran Adat kawin lari semakin meningkat di Desa Pinang Merah}

Berdasarkan hasil wawancara dengan beberapa informan dapat disimpukan bahwa pelanggaran adat kawin lari terus terjadi setiap tahunnya. Penyebab terjdinya kawin lari karena kurangnya pengawasan serta bimbingan dari orang tua. Orang tua kurang mengontrol anak sehinga anak telibat pergaulan bebas sehingga terjadi hal yang tidak diinginkan seperti kawin lari. Untuk mengurangi pelanggaran adat kawin lari tersebut anak membutuhkan pengawasan serta bimbingan orang tua agar tidak terjadi hal-hal yang tidak baik. Orang tua memiliki tanggung jawab mendidik, mengasuh dan membimbing anak-anaknya untuk mencapai tahap tertentu yang menghantarkan anak untuk siap dalam kehidupan masyarakat.

\section{Pelaksanaan sanksi adat kawin lari di Desa Pinang Merah}

Berdasarkan hasil wawancara dengan beberapa informan dapat disimpukan bahwa pelaksanan sanksi adat untuk kawin lari di Desa Pinang Merah belum berjalan dengan baik, karena masih ada masyarakat yang tidak mau membayar sanksi adat yang diberikan oleh lembaga adat, sebagai akibat telah melanggar adat. Tugas Lembaga Adat adalah melestarikan dan menumbuh kembangkan Adat istiadat dalam Desa Pinang Merah agar tetap diikuti oleh masyarakat dengan sepenuhnya. tidak ada lagi masyarakat yang tidak

\section{Persepsi masyarakat terhadap sanksi adat kawin lari di Desa Pinang Merah.}

Dari hasil wawancara dengan beberapa informan dapat disimpulkan bahwa persepsi masyarakat terhadap sanksi adat kawin lari yaitu sanksi adat merupakan suatu peraturan yang harus dipatuhi oleh masyarakat karena sudah temurun dari zaman dahulu yang masih dipakai samapai sekarang. Tetapi sanksi adat kawin lari belum terlaksana dengan baik karena adanya tebang pilih antar masyarakat. Karena tidak adanya ketegasan dari lembaga adat mengakibat masyarakat tidak mau membayar sanksi yang sudah di tetapkan oleh lembaga adat. Dalam memberikan sanksi kepada masyarakat yang melanggar adat harus ada ketegasan dari lembaga maupun pemerintah Desa agar masyarakat mematuhi aturan adat dengan baik.

\section{SIMPULAN}

berikut:

Dengan melihat dari hasil penilitian dan pembahasan maka dapat disimpilkan sebagai

1. Pelanggaran adat kawin lari terus terjadi setiap tahunnya. Karena kurangnya pengawasan dan bimbingan orang tua terhadap anak. Anak tidak dikontrol dengan baik, yang mengakibatkan anak terlibat pergaulan bebas. Kawin lari merupakan salah satu akibat dari pergaulan bebas.

2. Pelaksanaan sanksi adat kawin lari di Desa Pinang Merah belum terlaksana dengan baik. Karena masih banyak terjadi pelanggaran adat kawin lari dan masih banyak masyarakat yang tidak mau membayar sanksi adat yang telah ditetapkan oleh lembaga adat. Padahal sesuai dengan aturan lembaga adat di Desa Pinang Merah bagi yang melanggar adat seperti kawin lari akan dikenakan sanksi oleh lembaga adat yang harus dibayar oleh masyarakat.

3. Persepsi masyarakat terhadap sanksi adat kawin lari yaitu sanksi adat merupakan aturan yang harus dipatuhi oleh masyarakat. sanksi merupakan warisan turun temurun dari nenek moyang zaman dahulu yang masih dipakai sampai sekarang. Namun pada kenyataannya sanksi adat kawin lari belum terlaksana dengan baik karena masih terjadi tebang pilih atau pilih kasih antara masyarakat. 


\section{DAFTAR PUSTAKA}

Elly, Setiadi, dkk 2006. Ilmu Sosial \& Budaya Dasar. Jakarta: Kencana Media Group.

Dulbahri, 2017. Peraturan Adat Istiadat Desa Lubuk Gaung. Kecamatan Batang Masumai, Kabupaten Merangin.

Listyana \& Hartono, 2015.Persepsi Masyarakat terhadap Penanggalan Jawa dalam penentuan waktu pernikahan (studi kasus Desa Jonggrang Kecamatan Barat Kabupaten magetan Tahun 2013). IKIP PGRI, Madiun.

Manarsip marco, 2012. Eksistensi Pidana Adat dalam Hukum Nasional.Mahasiswa fakultas Hukum Universitas Sam ratulangi, Manado.

Mayangsari S. Ayu, 2017. Kajian Kesejahteraan Masyarakat. FKIP UMP.

Moleong, Lexy. J.2010. Metode Penelitian Kualitatif. Bandung: PT Remaja Rosdakarya

Peraturan Menteri Dalam Negeri Nomor 5 tahun 2007 tentang Pedoman Penataan Lembaga Kemasyarakatan. Jakarta

Sugiyono, 2010. Metode Penelitian Pendidikan Pendekatan Kuantitatif, Kualitatif dan R\&D. Bandung : Alfabeta

Suprapto,Ikhsan, dkk, 2017. Analisis faktor yang mempengaruhi pesepsi mahasiswa Utirta terhadap Perda syariah di Kota serang. Bandung.

Yazid \& Ridwan, 2017. Proses persepsi Diri Mahasiswa dalam berbusana muslimah.Riau. 